\title{
An Analysis of Service Quality Towards Customer Satisfaction Using Importance Performance Analysis (IPA) Method
}

\section{Analisis Kualitas Pelayanan terhadap Kepuasan Nasabah Menggunakan Metode Importance Performance Analysis (IPA)}

\author{
Dhea Arghisa'); Sulisti Afriani2); Abdul Rahman²) \\ 1)Study Program of Management, Faculty of Economic, Universitas Dehasen Bengkulu \\ ${ }^{2)}$ Department of Management, Faculty of Economic, Universitas Dehasen Bengkulu \\ Email: 1) arghisadhea@gmail.com; ${ }^{2)}$ sulistiafriani@unived.ac.id
}

How to Cite:

Arghisa, D., Afriani, S., Rahman, A. (2021). An Analysis of Service Quality Towards Customer Satisfaction Using Importance Performance Analysis (IPA) Method. EMAK: Jurnal Ekonomi Manajemen Akuntansi Dan Keuangan, 2(4). DOI: https://doi.org/10.53697/emak.v2i4

ARTICLE HISTORY

Received [12 Agust 2021]

Revised [25 Agust 2021]

Accepted [05 October 2021]

KEYWORDS

Importance Performance

Analysis (IPA), Service Quality,

Customer Satisfaction

This is an open access article under the $C C-B Y$-SA license

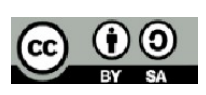

\section{ABSTRAK}

Tujuan penelitian ini adalah untuk mengukur tingkat kepuasan pelayanan yang diberikan oleh Bank Bengkulu Cabang Pembantu Ipuh kepada nasabah, mengetahui dimensi pelayanan yang diharapkan oleh nasabah (expected) dan yang diterima oleh nasabah (perceive) dan menguji beda (gap) antara kualitas pelayanan yang diharapkan oleh nasabah dengan kualitas pelayanan yang diterima oleh nasabah. Penelitian ini merupakan jenis penelitian deskriptif dengan pendekatan kuantitatif. Penelitian deskriptif adalah penelitian yang mengarah pada pengungkapan suatu masalah atau keadaan sebagaimana adanya dan mengungkapkan suatu fakta-fakta yang ada, walaupun kadang-kadang diberikan interpretasi atau analisis. Berdasarkan hasil perhitungan Indeks Kepuasan Pelanggan (IKP) Bank Bengkulu Cabang Pembantu Ipuh memperoleh skor total kepuasan pelayanan sebesar 64,64 yang termasuk kategori cukup memuaskan. Ada 5 dimensi kualitas layanan yang diuji, terdapat 1 dimensi dengan penilaian memuaskan yaitu dimensi bukti fisik $(69,76)$. Sedangkan 4 dimensi lainnya yaitu keandalan $(63,20)$, daya tanggap $(65,12)$, jaminan $(63,04)$ dan empati $(62,40)$ masing-masing mendapatkan penilaian cukup memuaskan. Berdasarkan hasil tersebut dapat disimpulkan bahwa tingkat kualitas pelayanan Bank Bengkulu Cabang Pembantu Ipuh sudah dirasa cukup memuaskan menurut nasabah Bank Bengkulu Cabang Pembantu Ipuh.

\section{ABSTRACT}

The purpose of this study was to measure the level of service satisfaction provided by Bank Bengkulu Sub-Branch Ipuh to customers, determine the dimensions of service expected by customers (expected) and those received by customers (perceive) and examine the difference (gap) between service quality expected by customers. customers with the quality of service received by customers. This research is a type of descriptive research with a quantitative approach. Descriptive research is research that leads to the disclosure of a problem or situation as it is and reveals an existing fact, although sometimes interpretation or analysis is given. Based on the results of the calculation of the Customer Satisfaction Index (IKP) Bank Bengkulu Ipuh Sub-Branch obtained a total service satisfaction score of 64.64 which is included in the quite satisfactory category. There are 5 dimensions of service quality tested, there is 1 dimension with a 
satisfactory assessment, namely the dimension of physical evidence $(69,76)$. While the other 4 dimensions, namely reliability (63.20), responsiveness (65.12), assurance (63.04) and empathy (62.40) each received a satisfactory rating. Based on these results, it can be concluded that the level of service quality of Bank Bengkulu Sub-Branch Ipuh is considered satisfactory according to customers of Bank Bengkulu SubBranch Ipuh.

\section{PENDAHULUAN}

Pada era globalisasi saat ini, persaingan dalam dunia bisnis semakin bertambah ketat. Persaingan ini menuntut para pelaku bisnis untuk mampu memaksimalkan kinerja perusahaannya agar dapat bersaing di pasar. Perusahaan harus berusaha keras untuk mempelajari dan memahami kebutuhan dan keinginan pelanggannya. Dengan memahami kebutuhan, keinginan dan permintaan pelanggan, maka akan memberikan masukan penting bagi perusahaan untuk merancang strategi pemasaran agar dapat menciptakan kepuasan bagi pelanggannya (Kotler dan Armstrong, 2009).

Pelanggan diibaratkan seorang raja yang harus dilayani, namun hal ini bukan berarti menyerahkan segala-galanya kepada pelanggan. Usaha memuaskan kebutuhan pelanggan harus dilakukan secara menguntungkan atau bersifat "win-win situation" yaitu dimana kedua belah pihak merasa senang atau tidak ada yang dirugikan. Kepuasan pelanggan merupakan suatu hal yang sangat berharga demi mempertahankan keberadaan pelanggannya tersebut untuk tetap berjalannya suatu bisnis atau usaha (Chandra dan Danny, 2015).

Kotler (2011) berpendapat bahwa perusahaan-perusahaan yang bergerak dalam bidang perbankan merupakan bisnis jasa yang berdasarkan pada azas kepercayaan sehingga masalah kualitas pelayanan menjadi factor yang sangat menentukan dalam keberhasilan usaha. Kualitas pelayananmerupakan suatu bentuk penilaian konsumen terhadap tingkat layanan yang diterima (perceived service) dengan tingkat layanan yang diharapkan (expected service). Agar dapat bersaing, bertahan hidup, dan berkembang, maka perusahaan perbankan dituntut untuk mampu memberikan pelayanan berkualitas yang dapat memenuhi kebutuhan dan keinginan pelanggan.

Bersamaan dengan hal tersebut pola pemikiran dan tingkat aktivitas secara mobile dari pelanggan saat ini juga ikut berkembang dan dibutuhkan lembaga penyedia atau lembaga yang memberikan jasa kemudahaan dalam aspek keuangan karena aspek keuangan merupakan bagian paling sensitif dari masyarakat, salah satu lembaga yang mampu menyediakan kemudahan tersebut ialah Bank. Dengan semakin meningkatnya mobilitas aktivitas dari masyarakat maka kemudahan yang diharapkan dari lembaga keuangan (Bank) juga ikut bertambah hal ini menjadi boomerang bagi pelaku usaha bidang keuangan (Bank) untuk selalu memenuhi kebutuhan dari masyarakat tersebut dan menimbulkan persaingan anatara pelaku usaha dibidang penyedia jasa keuangan (Bank) dalam hal mecapai kepuasaan pelanggan secara maksimal sehingga diharapkan loyalitas dari pelanggannya menjadi meningkat pula secara linear.

Salah satu lembaga penyedia jasa keuangan (Bank) yang harus memperhatikan dampak tersebut ialah Bank Pembangunan Daerah selanjutnya disingkat BPD, dimana BPD merupakan lembaga penyedia jasa keuangan yang sudah mulai marak berkembang di setiap daerah di Indonesia yang fokus utamanya pengelolaan dana dari pemerintah daerah baik itu APBD (Anggaran Pendapatan dan Belanja Daerah) maupun APBN (Anggaran Pendapatan dan Belanja Negara) yang di alokasikan untuk daerah. Tidak hanya terbatas dari pengelolaan tersebut BPD juga menjaring pelanggan dari segmen yang bukan bagian dari perangkat daerah atau negara namun juga dari segmen usaha maupun bisnis yang berkembang di daerah tersebut.Salah satunya ialah BPD yakni Bank Bengkulu yang berada di Provinsi Bengkulu.

Selain itu, semakin banyaknya persaingan dalam industri jasa perbankan memaksa Bank Bengkulu untuk mencari strategi yang paling tepat guna memenangkan persaingan. Salah satu strategi untuk meraih kesuksesan dalam industri jasa perbankan adalah dengan cara menciptakan 
kepuasan nasabah dengan meningkatkan kualitas pelayanan. Oleh karena itu, Bank Bengkulu sangat memprioritaskan kualitas produk dengan memberikan kualitas pelayanan dan fasilitasfasilitas unggulan yang tidak dimiliki oleh pesaing yang tentunya akan berakibat pada kepuasan yang diperoleh nasabah.

Penelitian ini dirancang untuk menganalisa tingkat kualitas pelayanan yang dilihat dari 5 dimensi yakni Keandalan (Reliabilities),Ketanggapan (Responsiveness), Jaminan (Assurance), Empati (Empathy), Bukti fisik (Tangibles) yang diberikan Bank Bengkulu terhadap pelanggan sehingga dapat memberikan efek terhadap Kepuasan Nasabah Bank Bengkulu dimana didalam pengukuran ini peneliti menggunakan Metode Importance Performance Analysis (IPA). Importance performance analysis adalah suatu teknik analisis yang digunakan untuk mengidentifikasi faktor-faktor kinerja penting apa saja yang harus ditunjukkan oleh suatu organisasi dalam memenuhi kepuasan para pengguna jasa (nasabah). Teknik ini mengidentifikasi kekuatan dan kelemahan penawaran pasar dengan menggunakan dua kriteria yaitu kepentingan relatif atribut dan kepuasan konsumen. Penerapan teknik ini dimulai dengan identifikasi atribut-atribut yang relevan terhadap suatu pilihan yang diamati.

\section{LANDASAN TEORI}

\section{Teori Kualitas Layanan}

Kualitas pelayanan terdiri dua faktor utama, yaitu expected service dan perceived service atau kulitas jasa yang diharapkan dan kulitas jasa yang diterima atau dirasakan. Apabila jasa yang diterima atau dirasakan sesuai dengan yang diharapkan, maka kualitas jasa dipersepsikan baik dan memuaskan. Jika jasa yang diterima atau dirasakan melampaui harapan konsumen, maka kualitas jasa dipersepsikan sebagai kualitas yang ideal. Sebaliknya jika jasa yang diterima lebih rendah daripada yang diharapkan maka kualitas jasa dipersepsikan sebagai kualitas yang buruk (Tjiptono,2014:59).

\section{Elemen Kualitas Layanan}

Menurut Parusaraman et al dalam (Tjiptono,2014:70):

1. Bukti Fisik

Bukti fisik (Tangible) meliputi fasilitas fisik, perlengkapan, pegawai, dan sarana komunikasi. Hal ini bias berarti penampilan fasilitas fisik, seperti gedung dan ruangan front office, tersedianya tempat parkir, keberhasilan, kerapian dan kenyamanan ruangan, kelengkapan peralatan komunikasi, dan penampilan karyawan. Prasarana yang berkaitan dengan layanan pelanggan juga harus diperhatikan oleh manajemen perusahaan.

Prasarana yang berkaitan dengan layanan konsumen juga harus diperhatikan oleh manajemen perusahaan. Gedung yang megah dengan fasilitas pendingin (AC), alat telekomunikasi yang canggih atau perabot kantor yang berkualitas, dan lain-lain menjadi pertimbangan konsumen dalam memilih suatu produk/jasa.

2. Keandalan

Keandalan (Reliability) merupakan kemampuan memberikan pelayanan yang dijanjikan dengan segera, akurat dan memuaskan. Hal ini berarti perusahaan memberikan jasanya secara tepat semenjak saat pertama (right the first time).

3. Daya Tanggap

Daya Tanggap (Responsiveness) merupakan keinginan para staf untuk membantu para konsumen dan memberikan pelayanan dengan tanggap. Daya tanggap dapat berarti respon atau kesigapan karyawan dalam membantu pelanggan dan memberikan pelayanan yang cepat dan, yang meliputi kesigapan karyawan dalam melayani pelanggan, kecepatan karyawan dalam menangani transaksi, dan penanganan.

4. Jaminan 
Jaminan (Assurance) mencakup pengetahuan, kemampuan, kesopanan, dan sifat dapat dipercaya yang dimiliki para staf; bebas dari bahaya, risiko atau keragu-raguan

5. Empati

Empati (empathy) merupakan kemudahan dalam melakukan hubungan, komunikasi yang baik, perhatian pribadi, dan memahami kebutuhan para konsumen. Setiap anggota perusahaan hendaknya dapat mengelola waktu agar mudah dihubungi, baik melalui telepon ataupun bertemu langsung. Dering telepon maksimal 3 kali, lalu segera djawab.

\section{Kepuasan Pelanggan}

Tjiptono (2014:45) menyatakan bahwa kepuasan atau ketidakpuasan pelanggan adalah respons pelanggan terhadap penilaian ketidak-sesuaian yang dirasakan antara harapan sebelumnya atau norma prestasi kerja lainnya dan prestasi kerja sebenar. Dalam konteks pelanggan umumnya harapan konsumen merupakan perkiraanatau keyakinan pelanggan tentang apa yang akan diterimanya. Harapan pelanggandiyakini mempunyai peranan besar dalam menentukan kualitas jasa dan kepuasanpelanggan.

Importance Performance Analysis (IPA)

Martilla dan James tahun 1977 memperkenalkan Importance Performance analysis (IPA) yang merupakan model multi-atribute dan dapat digunakan untuk menganalisis kinerja organisasi. Model IPA digunakan untuk mengukur kinerja kepuasan yang dianggap penting oleh pelanggan dan kinerja kepuasan yang diterima oleh pelanggan. Tujuan utama IPA adalah sebagai alat mendiagnostik untuk memudahkan mengidentifikasi atribut-atribut, yang didasarkan pada kepentingannya masing-masing, apakah produk atau jasa tersebut berkinerja buruk atau berkinerja berlebih (Algifari, 2016:124).oleh karena untuk mengetahui atribut apa saja yang harus diperbaiki, pada analisis IPA terdapat output berupa diagram yang memiliki 4 kuadran yaitu Kuadran A, kuadra B, kuadran C, dan kuadran B.

\section{METODE PENELITIAN}

\section{Metode Analisis}

Penelitian ini merupakan jenis penelitian deskriptif dengan pendekatan kuantitatif. Penelitian deskriptif adalah penelitian yang mengarah pada pengungkapan suatu masalah atau keadaan sebagaimana adanya dan mengungkapkan suatu fakta-fakta yang ada, walaupun kadangkadang diberikan interpretasi atau analisis (Sugiyono,2013:12). Hasil dari penelitian ini difokuskan untuk menggambarkan keadaan sebenarnya dari obyek yang diteliti. Penelitin kuantitatif adalah penlitian yang banyak dituntut menggunakan angka, mulai dari pengumpulan data, penafsiran data serta penampilan dari hasilnya (Arikunto,2010:12). Penelitian deskriptif dan kuantitatif merupakan penelitian yang menggunakan suatu fakta, gejala, fenomena, opini atau pendapat secara cermat dan sistematis.

Data yang telah diolah kemudian dianalisis melalui tiga tahap. Tahapan analisis kualitas pelayanan terhadap kepuasan yang diterima oleh pelanggan.

Indeks Kepuasan Pelanggan

Ukuran kualitas pelayanan oleh Bank Bengkulu Cabang Pembantu Ipuh kepada pelanggan menggunakan Indeks Kepuasan Pelanggan (IKP), kinerja kualitas pelayanan ditentukan dengan rumus:

$$
\text { Interval Kelas }=\frac{\text { Skor Tertinggi }- \text { Skor Terendah }}{\text { Banyaknya Kategori }} \text { Sumber: Algifari }(2016,132)
$$

Skor tertinggi masing-masing pertanyaan adalah lima dan skor terendah adalah satu, sedangkan banyaknya penilaian (kelas) adalah lima. Dengan demikian besarnya interval kelas untuk menentukan kepuasan pelanggan atas pelayanan Bank Bengkulu Cabang Pembantu Ipuh adalah: 
Interval Kelas $=\frac{5-1}{5}=0,80 \quad$ (Sumber: Algifari,2016)

Jarak penilaian sebesar 0,80 sehingga diperoleh kriteria kategori:

\section{HASIL DAN PEMBAHASAN}

\section{Hasil dan Pembahasan}

Pada bagian ini dibahas mengenai pemetaan dari nilai kinerja dan harapan, dari hasil tersebut maka akan terbentuk matriks yang terdiri dari empat buah kuadran yang masing-masing menggambarkan skala prioritas dalam mengambil kebijakan baik berupa peningkatan kinerja atau mempertahankan kinerja perusahaan. Berikut ini adalah data sebaran kinerja dan harapan nasabah :

Gambar 1. Diagram Kartesius IPA

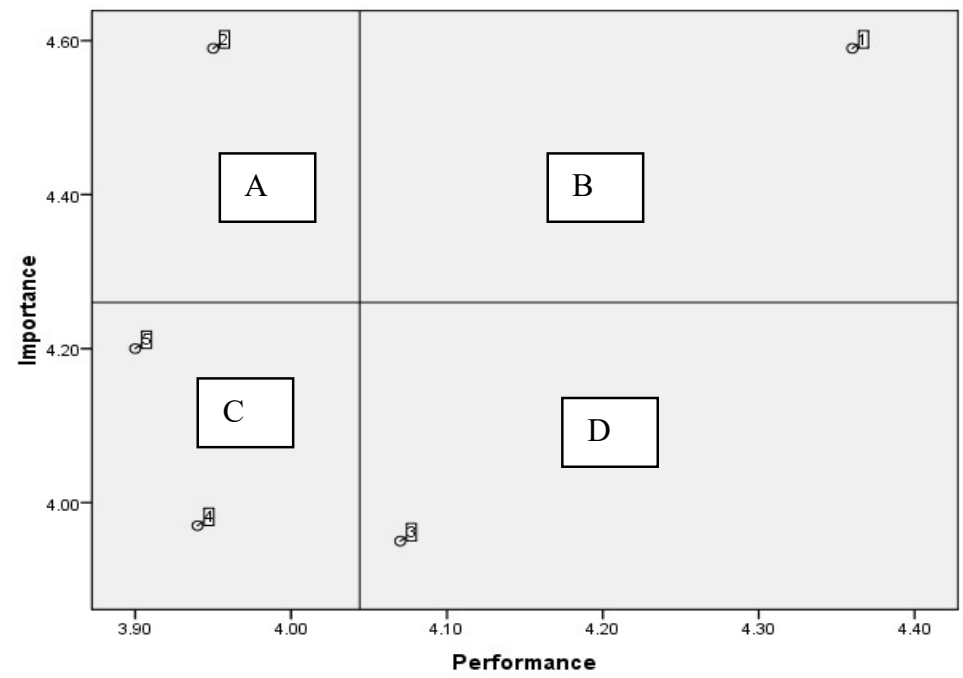

Sumber: Hasil Penelitian, Data diolah (2020)

Keterangan: 1. Bukti Fisik, 2. Keandalan, 3. Daya Tanggap, 4. Jaminan, 5. Empati

Berdasarkan Gambar dapat dianalisis kualitas pelayanan Bank Bengkulu Cabang Pembantu Ipuh sebagai Berikut:

1. Kuadran A (Prioritas Utama), pada kuadran ini menunjukkan dimensi yang mempengaruhi kepuasan nasabah Bank Bengkulu Ipuh, dalam kuadran ini perlu diprioritaskan oleh perusahaan karena dinilai sangat penting oleh nasabah, sedangkan tingkat pelaksanaannya masih belum memuaskan nasabah. Adapun dimensi yang masuk pada kuadran A yaitu dimensi keandalan.

2. Kuadran B (Pertahankan Prestasi) terdapat 1 dimensi yaitu dimensi bukti fisik, artinya kualitas layanan berupa dimensi bukti fisik dinilai penting oleh nasabah, dan Bank Bengkulu Cabang Pembantu Ipuh sudah melakukan kinerja yang baik pula. Oleh karena itu diharapakan kepada Bank Bengkulu Cabang Pembantu Ipuh dapat mempertahankan kinerjanya.

3. Kuadran C (Prioritas Rendah) dimensi yang termasuk dalam kuadran C yaitu dimensi jaminan dan empati ini menunjukkan bahwa dimensi jaminan dan empati dinilai masih kurang penting oleh nasabah dan kualitas pelayanan yang diberikan Bank Bengkulu Cabang Pembantu Ipuh juga rendah.

4. Kuadran D (Berlebihan) terdapat 1 dimensi yaitu dimensi daya tanggap, artinya nasabah Bank Bengkulu menilai dimen daya tanggap ini tidak terlalu penting, tetapi Bank Bengkulu Cabang Pembantu Ipuh memberikan pelayanan dengan kualitas yang tinggi. Oleh karena itu 
perusahaan dapat mengalihkan kinerja yang berlebihan ini, dengan meningkatkan kinerja pada dimensi keandalan agar kualitas layanan menjadi lebih baik.

\section{Uji Wilcoxon Signed Rank}

Tahap ketiga analisis adalah melakukan uji hipotesis beda antara kepuasan pelayanan yang diharapkan oleh pelanggan dengan kepuasan pelayanan yang diterima oleh pelanggan menggunakan uji Wilcoxon Signed Rank. Hipotesis nol dalam pengujian ini menyatakan bahwa tidak terdapat perbedaan antara kepuasan pelayanan yang diharapkan oleh pelanggan dengan kepuasan pelayanan yang diterima oleh pelanggan, sedangkan hipotesis alternatif dalam pengujian menyatakan terdapat perbedaan antara kualitas pelayanan yang diterima oleh nasabah dengan kualitas pelayanan yang diharapkan oleh nasabah. Penelitian ini dilakukan dengan menggunakan tingkat signifikansi $(\alpha)=0,05$ dengan nilai $Z$ tabel adalah $-1,56$. Berikut hasil perhitungan SPSS $Z$ hitung (berdasarkan lampiran 9):

Tabel 1. Hasil Perhitungan Uji Wilcoxon Sign Rank

\begin{tabular}{|l|l|r|l|}
\hline \multirow{2}{*}{ Dimensi } & \multicolumn{2}{|c|}{ Test Statistics } & \multirow{2}{*}{ Kesimpulan } \\
\cline { 2 - 3 } & Z Hitung & Sig & \\
\hline Bukti Fisik & $-3,024$ & 0,002 & Terdapat perbedaan \\
\hline Keandalan & $-8,025$ & 0,000 & Terdapat perbedaan \\
\hline Daya Tanggap & $-2,123$ & 0,034 & Terdapat perbedaan \\
\hline Jaminan & $-1,089$ & 0,276 & Tidak Terdapat perbedaan \\
\hline Empati & $-5,753$ & 0,000 & Terdapat perbedaan \\
\hline
\end{tabular}

\section{Sumber : Hasil Penelitian,Data diolah (2020)}

Dimensi bukti fisik pada hasil pengujian memperoleh Z hitung -3,024 lebih besar nilai Z tabel yaitu $-1,56$ atau sig. 0,002 <0,05. Dari hasil pengujian bukti fisik diperoleh keputusan untuk menerima hipotesis alternatif $(\mathrm{Ha})$ yang menyatakan bahwa terdapat perbedaan antara kualitas layanan yang diterima dengan kualitas layanan yang diharapkan oleh nasabah pada dimensi bukti fisik. Kualitas layanan yang diharapkan oleh nasabah Bank Bengkulu Cabang Pembantu Ipuh lebih besar daripada yang diterima ini terlihat dari tanda (a) pada $\mathrm{Z}$ hitung.

Untuk dimensi keandalan pada hasil pengujian memperoleh $Z$ hitung $-8,025$ lebih besar dari nilai $Z$ tabel yaitu $-1,56$ atau sig. 0,000 $<0,05$. Dari hasil pengujian keandalan diperoleh keputusan untuk menerima hipotesis Ha yang menyatakan bahwa terdapat perbedaan antara kualitas layanan yang diterima dengan kualitas layanan yang diharapkan oleh nasabah pada dimensi Keandalan. Kualitas layanan pada dimensi keandalan yang diharapkan oleh nasabah Bank Bengkulu Cabang Pembantu Ipuh lebih besar daripada yang diterima oleh nasabah ini terlihat dari tanda (a) pada Z hitung.

Untuk dimensi daya tanggap pada hasil pengujian memperoleh Z hitung -2,123 lebih besar dari nilai $Z$ tabel yaitu $-1,56$ atau sig. 0,034<0,05. Dari hasil pengujian dimensi daya tanggap diperoleh keputusan untuk menerima hipotesis Ha yang menyatakan bahwa terdapat perbedaan antara kualitas layanan yang diterima dengan kualitas layanan yang diharapkan oleh nasabah pada dimensi daya tanggap. Kualitas layanan pada dimensi daya tanggap yang diharapkan oleh nasabah Bank Bengkulu Cabang Pembantu Ipuh lebih besar daripada yang diterima oleh nasabah ini terlihat dari tanda (a) pada Z hitung.

Untuk dimensi jaminan pada hasil pengujian memperoleh $Z$ hitung -1.089 lebih kecil dari nilai $Z$ tabel yaitu $-1,56$ atau sig. 0,276 $>0,05$. Dari hasil pengujian jaminan diperoleh keputusan untuk menolak hipotesis Ha. Dengan demikian berdasarkan hasil pengujian dimensi jaminan dapat ditarik kesimpulan bahwa tidak terdapat perbedaan antara kualitas layanan dimensi jaminan yang diharapkan oleh nasabah Bank Bengkulu Cabang Pembantu Ipuh dengan kualitas layanan yang diterima oleh nasabah Bank Bengkulu Cabang Pembantu Ipuh. 
Untuk dimensi empati pada hasil pengujian memperoleh $Z$ hitung $-5,753$ lebih besar dari nilai Z tabel yaitu $-1,56$ atau sig. 0,000 $<0,05$. Dari hasil pengujian empati diperoleh keputusan untuk menerima hipotesis Ha yang menyatakan bahwa terdapat perbedaan antara kualitas layanan yang diterima dengan kualitas layanan yang diharapkan oleh nasabah Bank Bengkulu Cabang Pembantu Ipuh pada dimensi empati. Kualitas layanan pada dimensi empati yang diharapkan oleh nasabah Bank Bengkulu Cabang Pembantu Ipuh lebih besar daripada yang diterima oleh nasabah ini terlihat dari tanda (a) pada Z hitung.

\section{KESIMPULAN DAN SARAN}

\section{Kesimpulan}

\section{Indeks Kepuasan Pelanggan}

Skor kepuasan pelayanan yang didapatkan oleh Bank Bengkulu Cabang Pembantu Ipuh yaitu sebesar $64,64 \%$ termasuk dalam kategori cukup memuaskan. Dari 5 dimensi yang diuji terdapat satu dimensi dengan penilaian memuaskan yaitu dimensi bukti fisik, sedangkan 4 dimensi lainnya yaitu keandalan, daya tanggap, jaminan dan empati mendapatkan penilaian cukup memuaskan.

\section{Diagram Kartesius IPA}

Pada analisis hasil diagram kartesius dimensi yang menjadi prioritas utama Bank Bengkulu Cabang Pembantu Ipuh untuk perbaikan yaitu dimensi keandalan, ini dianggap penting oleh nasabah Bank Bengkulu Cabang Pembantu Ipuh tetapi Bank Bengkulu belum memberikan pelayanan yang maksimal. Dimensi yang harus dipertahankan kinerjanya yaitu dimensi bukti fisik, ini dianggap penting oleh nasabah Bank Bengkulu Cabang Pembantu Ipuh dan Bank Bengkulu Cabang Pembantu Ipuh sudah melakukan kinerja dengan baik. Lalu untuk dimensi yang menjadi prioritas rendah jaminan dan empati, ini dianggap tidak penting dan Bank Bengkulu Cabang Pembantu Ipuh juga memberikan pelayanan kualitas rendah..Sedangkan untuk dimensi yang dianggap berlebihan yaitu dimensi daya tanggap, ini dianggap tidak penting oleh nasabah tetapi Bank Bengkulu Cabang Pembantu Ipuh memberikan pelayanan dengan kualitas tinggi.

\section{Uji Wilcoxon Signed Rank}

Pengujian statistik dengan uji wilcoxon signed rank terdapat 4 dimensi yaitu dimensi bukti fisik, keandalan, daya tanggap, dan empati yang menjukkan adanya perbedaan antara kualitas layanan yang diharapkan oleh nasabah Bank Bengkulu Cabang Pembantu Ipuh dengan kualitas layanan yang diterima oleh nasabah Bank Bengkulu Cabang Pembantu Ipuh. Sedangkan untuk dimensi jaminan dari hasil uji wilcoxon yang sudah dilakukan menunjukkan tidak adanya perbedaan antara kualitas layanan yang diharapkan oleh nasabah Bank Bengkulu Cabang Pembantu Ipuh dengan kualitas layanan yang diterima oleh nasabah Bank Bengkulu Cabang Pembantu. Dengan kata lain nasabah Bank Bengkulu Cabang Pembantu Ipuh cukup puas dengan kualitas layanan yang diberikan.

\section{Saran}

1. Untuk Bank Bengkulu Cabang Pembantu Ipuh perlu memperbaiki atribut-atribut kualitas pelayanan yang telah diberikan pada setiap dimensinya, terutama atribut yang menjadi prioritas utama/kuadran A yaitu atribut pada dimensi keandalan. Dimana salah satu atribut pada dimensi keandalan yaitu ketepatan waktu jam pelayanan, diharapkan petugas pelayanan Bank Bengkulu Cabang Pembantu Ipuh dapat memperbaiki atribut ini.

2. Untuk memperbaiki atribut-atribut yang menjadi prioritas utama yang dapat dilakukan perusahaan adalah membuat komitmen dengan masing-masing petugas pelayanan agar dapat melaksanakan tugasnya sesuai standar pelayanan yang telah ditetapkan oleh Bank Bengkulu. 


\section{DAFTAR PUSTAKA}

Algifari, 2016. Mengukur Kualitas Pelayanan dengan Indeks Kepuasan, Metode Importance Performane Analysis (IPA) dan Model Kano. Yogyakarta: BPFE.

Robert,Africo. 2019. Analisis Kepuasan Pelayanan pada Pelanggan Perusahaan Daerah Air Minum (PDAM) Kota Bengkulu dengan Metode (Impotance Performance Analysis (IPA) di Universitas Dehasen. Skripsi tidak diterbikan. Bengkulu, Fakultas Ekonomi Universitas Dehasen.

Sugiyono, 2013. Metode penelitian pendidikan: pendekatan kuantitatif, kualitatif, dan R \& D. Bandung: Alfabeta

Tjiptono, F. 2014. Pemasaran Jasa (Prinsp, Penerapan, Penelitian). Yogyakarta: Andi Ofset

Kamus Umum Bahasa Indonesia. 2014. Diakses melalui website. www.kamusbesarbahasaindonesia.com

Kusumawati dan Kumadji, S., 2016, "Analisis Faktor-Faktor Pembentuk Electronic Word-of-Mouth (eWOM) dan Pengaruhnya Terhadap Minat Beli (Survei pada Followers Akun Instagram @saboten_shokudo)", Jurnal Administrasi Bisnis (JAB), Vol. XXXVII 1, Agustus, hal. 148-15

Lestari. 2017. Pengaruh Kesadaran Wajib Pajak Dan Sanksi Pajak Terhadap Kepatuhan Wajib Pajak Orang Pribadi Pada Kantor Pelayanan Pajak Pratama Batam. Journal of Accounting \& Management Innovation, Vol.1 No.2, July 2017

Lumbantoruan, Amber. 2012. Analisis Perbedaan Perhitungan Laba Kena Pajak Menurut Laporan Keuangan Komersial dan Laporan Keuangan Fiskal. Jurnal IImiah Akuntansi, Vol. 1 (2): 21-30

Mardiasmo. 2016. Perpajakan Edisi Revisi Tahun 2016. Yogyakarta:Penerbit Andi.

Notosoedirjo Moeljono dan Latipun. 2012. Kesehatan Mental (Konsep Penerapannya). Malang: UMM Press.

Nurmantu, Safri. 2010. Pengantar Perpajakan. Jakarta: Kelompok Yayasan Obor

Oladipupo dan Obazee. 2016. Perencanaan Perpajakan . Jakarta: PT Bumi Aksara

Rachman, Rinda dan Gita. 2017. Faktor-Faktor Yang Mempengaruhi Keberhasilan Penerimaan Pajak Daerah. Bandung: PT Refika Aditama.

Safri Nurmantu. 2010. Pengantar Perpajakan. Jakarta: Kelompok Yayasan Obor

Singarimbun, Masri dan Sofian Effendi. 2012. Metode Penelitian Survei. Jakarta: LP3ES

Situs pajak: https://www.pajak.go.id/

Soemitro. 2014. Asas dan Dasar Perpajakan 1 dan 2. Bandung: PT Refika Aditama.

Sugiyono. 2013. Metode Penelitian Kuantitatif, Kualitatif dan R\&D. Bandung: CV. Alfabeta

Sulistyiwati, Diah. 2011. Pengaruh Pajak Daerah, Retribusi Daerah, Dana Alokasi Umum, dan Dana Alokasi

Wulandari. 2016. Pendekatan Penganggaran Daerah dan Akuntansi Keuangan Daerah. Badan Penerbit Universitas Diponegoro Semarang. 